\title{
Choosing remedies after accidents: Counterfactual thoughts and the focus on fixing "human error"
}

\author{
MICHAEL W. MORRIS, PAUL C. MOORE, and DAMIEN L. H. SIM \\ Stanford University, Stanford, California
}

\begin{abstract}
The present research is motivated by an interest in why organizational decision makers so often respond to accidents with remedy plans that focus narrowly on correcting human error rather than more environment-focused plans or more encompassing plans. We investigated the role of counterfactual thinking in the decision-making tendency toward human-focused plans. Our experiments indicated that even in a domain where human-focused remedies were not otherwise appealing, many participants decided on human-focused remedies after they had generated an "if only" conjecture about the accident. This reflects that human actions are often selected as the focus of "if only" conjectures and, importantly, that this focus "locks in" and carries through to subsequent remedy decisions. Our hypothesis that remedy plans are produced from "if only" thoughts was supported over several alternative interpretations. We discuss implications for research on the relation between counterfactual thinking and adaptive learning.
\end{abstract}

Accidents incite judgment and decision making. Responses to accidents have captured the interest of organizational researchers studying actual decisions in field settings (March \& Simon, 1958) and of cognitive psychologists studying decisions in laboratory tasks (Kahneman \& Tversky, 1982). Among the more important insights from organizational research is that when managers choose remedies after accidents, they often focus on human factors to the exclusion of relevant factors in workers' environments (Perrow, 1984; Vaughan, 1996). Organizational researchers have also drawn attention to institutionalized procedures of analyzing accidents, such as the practice of identifying a "root cause" through a reconstructive simulation of the chain of events (Carroll, 1995). Interestingly, these procedures require a strategy of diagnosis like that which cognitive psychologists have called "counterfactual thinking" or "if only" thinking (Kahneman \& Miller, 1986; Kahneman \& Tversky, 1982). The present research takes this parallel as a point of departure. We build on evidence from research on academic tasks suggesting that people's "if only" conjectures about a negative outcome shape their subsequent plans for preventing recurrences (Roese, 1994). We hypothesize "if only" conjectures after accidents shape the focus of subsequent remedy decisions. Hence, "if only" conjectures focusing on actions of employees would lead to

We would like to thank Pam Haunschild, Itamar Simonson, Jim March, and Vittorio Girotto for their helpful comments, and Aimee Drolet and Steve Su for assisting in the coding. A more detailed report of empirical resuits is available on request from the authors. Correspondence should be addressed to M. W. Morris, Graduate School of Business, Stanford University, Stanford, CA 94305-5015 (e-mail: morris_michael@ gsb.stanford.edu). plans to change the employees rather than changing their environment.

Before introducing the studies testing our hypothesis about the role of "if only" conjectures in shaping remedy decisions, we shall first review some related literature that highlights the importance of this hypothesized influence on remedy decision making. First, we will review conclusions from field research on industrial accidents about the context and patterns of remedies chosen to prevent accident recurrences. Next we will review evidence from research on the heuristics guiding "if only" thinking.

\section{Responses to Accidents in Organizations}

An enduring idea in organizational research is that managerial decisions are often made through standard operating procedures rather than through thorough analysis (March \& Simon, 1958). Although the solutions provided by such procedures are not always optimal, managers tend to settle on the first plausible solution rather than search more exhaustively for the optimal solution - "satisficing" rather than optimizing (March, 1994). In many industries, the standard procedure for responding to an accident is to identify a "root cause" (Carroll, 1995). To do this, a decision maker reconstructs or simulates the chain of events leading to the accident. After large disastrous accidents, such as those involving the Three Mile Island nuclear plant or the Space Shuttle Challenger, such reconstructions have become public, drawn-out affairs. After smaller accidents, the same process occurs in miniature as a manager prepares to report on the root cause of the accident.

Responding to an accident by searching for the root cause of a given outcome can be contrasted with other ways of analyzing the problem. A different approach is to consider the current accident as one case in a larger data set 
of accidents and nonaccidents in the organization's experience and to analyze the covariation of outcomes and causal factors (see Kelley, 1967). Evidence both from the laboratory and from the field suggests that a failure to consider a given case in light of past cases prevents discovery of some causal factors that may be important. The laboratory research of McGill (1989) has shown that discovery of some causal factors requires that the current case be compared with past cases-that participants implicitly ask, "Why did the outcome occur on this occasion and not on past occasions?" Organizational research on accident diagnoses suggests a similar pattern. In the case of the Three Mile Island nuclear plant, the initial diagnosis, based on a close reconstruction of the accident event, was revised when the accident was analyzed in the context of the organization's historical experience with related incidents (Perrow, 1981). Similarly, the initial attribution of the Challenger disaster to an inappropriate launch decision was qualified after broader analysis (Vaughan, 1996). ${ }^{1}$

Another theme in organizational research on responses to accidents is the tendency of decision makers to focus on human factors rather than factors in the machine or organizational environment. Studies across industries confirm that the most prevalent diagnosis of industrial accidents is "human error," and remedies tend to focus on changing human factors (through replacing or retraining employees) rather than changing machine or organizational factors (Norman, 1990, 1992). In Vaughan's (1996) words, "invariably, the accepted explanation [for industrial accidents] is some form of 'operator error,' isolating in the media spotlight someone responsible for the hands-on work: the captain of the ship, a political functionary, a technician, or middle-level managers" (p. 393). In the aviation industry, for example, $75 \%$ of fatal aviation accidents in a recent 5-year-period were blamed on pilot error (National Traffic Safety Board, 1990). The percentage of accidents attributed to human error may be greater than deserved because of the cognitive processes involved after accidents.

The mere prevalence of a focus on "human error" does not necessarily indicate nonoptimal decision making. In some domains of organizational accidents, human-focused remedies may be the only sort feasible. Or, human-focused remedies may be more efficacious than other possible remedies that focus on the environment or on interactions of factors. Nevertheless, there are some domains that do not fit these descriptions, and yet human-focused remedies are favored (Norman, 1990). The present research investigates a possible contributor to human-focused remedy decisions in accident domains where human-focused remedies are not the only possible remedy or the most efficacious remedy. We propose that a prompt for "if only" thinking leads to an early narrowing of focus on a single factor, often a human action, and this focus "locks in" and carries through to remedy decisions.

\section{"If Only ..." Conjectures and Remedy Decisions}

Accidents have been studied by psychologists interested in people's thinking about counterfactual or "might have been" scenarios (Kahneman \& Miller, 1986; Kahneman \& Tversky, 1982). One form of counterfactual thinking that occurs after negative, unexpected outcomes such as accidents is expressed by conjectures that the outcome could have been averted "if only" one antecedent event had been changed. An interesting feature of "if only" conjectures is that they emphasize how a change to only one factor could have made a difference. The outcome is traced to a single, critical link in the causal chain. By contrast, other ways of framing explanations for an outcome foster more emphasis on combinations of multiple factors. The narrow focus of "if only" conjectures has led researchers to study how people select one focal factor from the many possible factors antecedent to an outcome (Roese, 1997; Wells, Taylor, \& Turtle, 1987). Research on this question has uncovered heuristics guiding the focus of "if only" conjectures, such as that human actions are favored over nonhuman factors having the same causal relationship to the outcome (Girotto, Legrenzi, \& Rizzo, 1991). An account for this tendency is that human actions are more "mentally nutable" than other factors; that is, it is easier to imagine a change in human action (a person having done $\mathrm{x}$ instead of $\mathrm{y}$ ) than to imagine a change in an environmental factor (the replacement of one machine with a different machine). Importantly, the relative ease of bringing to mind the alternative human behavior $x$ does not mean that this behavior would be relatively easy to bring about in reality. In reality, changing environmental factors might be easier than controlling human behavior. ${ }^{2}$

In the present research, we test the hypothesis that human-focused remedy decisions are caused by humanfocused "if only" conjectures. A precedent for the notion that remedy decisions are directly shaped by initial "if only" conjectures comes from research on individual academic performance (Roese, 1994). There is both laboratory and field evidence that the content of students' "if only" conjectures after negative feedback determines the content of their plans for improved performance in the future (Roese, 1994; Roese \& Olson, 1995). Certain kinds of "if only" conjectures beget certain kinds of corrective plans. In this vein, we hypothesize that human-focused "if only" conjectures may lead to human-focused remedy decisions.

\section{PILOT STUDY}

The tendency for "if only" conjectures to engender human-focused remedy decisions is of greatest interest in domains where human-focused remedies would not be otherwise chosen. We sought to study a type of accident in which human-focused remedies are often chosen even though they are rejected by people who fully evaluate a variety of different remedy plans. In designing our vignette, we drew on studies of industrial accidents that point to situations where human operators have to respond to changes in the machine environment (Norman, 1992; Reason, 1990). Girotto et al. (1991) provided the everyday example of how a driver of an old car compensates for the 
machine's degradation by developing skills that take over functions once handled by the machine, such as signaling. In so doing, the driver's role becomes more salient. After an accident, this driver is a more likely focus of blame and remedy attempts than would be the driver of a new, fully functioning car. Yet it is precisely in the case of the old car, not the new car, where diagnosis and remedy should focus on the machine rather than on its human operator. A larger example of this pattern of remedy decisions for this type of accident was the recent termination of the Russian cosmonauts involved in accidents on the space station, Mir, even though the accidents occurred during their efforts to repair components that had stopped functioning (Specter, 1997). ${ }^{3}$ Norman (1992) presented case studies of industrial settings where the focus on the human side of the human-machine interface led to a failure to prevent recurrences of easily avoidable accidents. In our pilot study, we presented a description of an accident of this type and checked how participants would analyze the strengths and weaknesses of human and environment-focused plans for remedying the problem.

\section{Method}

We presented 54 undergraduates at a major California university a story entitled "Accident at the Lawn Mower Factory," which described a factory that had recently started to produce a new lawn mower product:

The new lawn mower is built on the same assembly line as the old one was but has required a few changes in the manufacturing process.

The story continued by describing how workers have reacted to the change:

After the change, some assembly line workers have grumbled that mowers no longer arrive to their work station in a steady flow. One complained about "rushing to finish the first mower in time for a second, but then having to wait forever for the third to arrive." Long-time workers have started the practice of "reaching up the line" to work on a mower before it is secured at their work stations. This has nearly caused accidents, and the foreman has cautioned against it.

Next was a description of the accident:

Today an accident occurred in the factory that resulted in a line shutdown for over three hours. Paul, a long-time worker was "reaching up the line," lost his balance, and caused a mower to fall on some delicate quality control instruments.

The story ended by conveying that "in addition to the high replacement costs of the broken instruments, the lost production of this highly demanded product is extremely costly for the company."

We assessed participants' responses by asking them to consider two general approaches to preventing accidents, "changing the workers" and "changing the work environment." "Changing the workers" was defined as either hiring different people or training the current people into different modes of behavior. "Changing the work environment" was defined as redesigning the organizational policies or the physical structure of the setting or the machinery. Participants were told that both options were fiscally feasible and were asked to consider these two options with respect to several criteria. Three items captured different aspects of the perceived efficacy of a solution: "Is this approach likely to solve the problem completely?" "Is this approach likely to provide a lasting solution?" and "Could this approach, by itself, eliminate the problem of reaching-related accidents?" A final item probed the perception that a particular remedy would not only be inefficacious but also counterproductive (i.e., "Is it likely that this solution will be counterproductive?"). All ratings were taken on a Likert-type scale $(1=$ not at all; $7=$ very much $)$.

\section{Results}

Because of the intercorrelation among the items tapping the perceived efficacy of changing the workers (mean $r=.50$ ) and changing the environment (mean $r=.32$ ), indices were formed by averaging the three ratings for each remedy. We submitted these to a repeated measures analysis of variance (ANOVA) and found that participants judged human-focused changes to be far less efficacious $(M=3.31)$ than changes to the work environment $[M=$ $5.51 ; F(1,50)=74.64, p<.001]$. Another way to summarize the results in evaluating the strengths of the two plans was that human-focused plan was rated better by only $13 \%$ of participants.

Ratings of weaknesses of the plans showed a consistent pattern. The likelihood of counterproductive results was rated higher for a human-focused intervention ( $M=$ 4.26) than an intervention focused on the work environment $[M=3.31 ; F(1,50)=9.37, p<.005]$.

In sum, results reveal that participants who thoroughly consider decision options recognize the relative limitations of human-focused remedies in this accident context. The new assembly line creates a strong temptation to reach up the line, so retraining or replacing the workers would be unlikely to prevent a recurrence. ${ }^{4}$

\section{EXPERIMENT 1}

Experiment 1 presented the same accident case as in the pilot study, but introduced a prompt to respond to the accident with an "if only" thought. We put several groups of participants in the role of a manager responding to the accident at the lawn mover factory. With several different formats, we checked the association between the content of "if only" conjectures and of subsequent remedy decisions.

\section{Method}

Two groups of participants were put in the role of manager and asked to respond to the lawn mower accident story described above. These different replications, in which the format of measures also varied, will be reported as Experiments 1A and 1B.

Experiment 1A. A group of management students $(n=58)$ were prompted to make "if only" conjectures in response to the outcome and then to make decisions about how to remedy the problem. Their counterfactual task asked them to complete a sentence beginning "If only ..." and ending with "this accident would not have happened." This allowed us to assess the factors on which people spontaneously focus on when undoing an accident. Afterward, participants were told to suppose that the factory allowed a limited amount of funds to use in trying to reduce the chances of future accidents. They were told to consider the options of doing nothing at all, of trying to change employees' behavior, and of trying to change the machine environment. Participants then wrote a summary of their decision.

Experiment 1B. To check whether the findings generalize beyond the population of management students, museum goers $(n=$ 93) were asked to choose which of two options was more similar to their own intuitive reaction to the accident. The counterfactual op- 
Table 1

Frequency of Person- and System-Focused Remedies

by Managers as a Function of Having Generated Person-

and System-Focused "If Only" Statements in Experiment 1A

\begin{tabular}{|c|c|c|c|c|c|c|c|}
\hline \multirow[b]{3}{*}{ Remedy Focus } & \multicolumn{7}{|c|}{ "If Only" Conjecture Type } \\
\hline & \multicolumn{2}{|c|}{$\begin{array}{l}\text { Worker Had } \\
\text { Not Reached }\end{array}$} & \multicolumn{2}{|c|}{$\begin{array}{c}\text { Assembly Line } \\
\text { Was Designed Better }\end{array}$} & \multicolumn{2}{|c|}{ Other } & \multirow[b]{2}{*}{ Total } \\
\hline & $n$ & $\%$ & $n$ & $\%$ & $n$ & $\%$ & \\
\hline Retrain workers & 15 & 56 & 3 & 13 & 3 & 38 & 21 \\
\hline Redesign line & 11 & 41 & 18 & 78 & 2 & 25 & 31 \\
\hline Other & 1 & 4 & 2 & 9 & 3 & 38 & 6 \\
\hline Total & 27 & & 23 & & 8 & & 58 \\
\hline
\end{tabular}

Note $-\chi^{2}(1,58)=17.79, p<.001$

tions were, "If only Paul had not reached up the line, the accident would not have happened," and "If only the assembly line had been designed to deliver engines in a steady flow, the accident would not have happened." Later, they were presented with two remedy options and asked to select the one that they would recommend. The remedy options were, "Educate the workers about unsafe behaviors on the assembly line," and "Investigate possible design changes to the assembly line."

\section{Results}

In Experiment 1 A, both the "if only" conjectures and remedy plans were coded into three categories: (1) those focused on the human operator of the machine, (2) those focused on the machine environment, and (3) those focused elsewhere. Two coders agreed on over $90 \%$ of the cases. In counterfactual conjectures, the modal response ( $47 \%$ of participants) focused explicitly on the worker's action ("If only Paul hadn't reached up the line"). A considerable fraction of responses $(40 \%)$ focused on the assembly line, and the remaining fraction (13\%) focused on other aspects of the worker's environment such as the management. In response to the remedy decision task, a large fraction of participants (36\%) generated plans that focused narrowly on changing the employees' behavior (e.g., "Hold workshops to change the workers' behavior"). (Notice that although this is not a majority of participants, the rate of preference for human-focused remedies is strikingly higher than the $13 \%$ rate at which participants in the pilot study favored human-focused over environmentfocused plans.) The remaining participants addressed the problem through either a redesign of the assembly line (53\%; e.g., "plan to regularize the assembly line flow so that it is steady and continuous") or some other approach ( $10 \%$; e.g., "bring in a consultant" or "do nothing").

Although the increased frequency of preference for human-focused remedies (relative to the pilot study) suggests support for the hypothesis, more direct evidence comes from looking at remedy decisions conditional on participants' "if only" thoughts, as shown in Table 1. Among participants who went down the cognitive path of a human-focused "if only" conjecture, $56 \%$ decided on a human-focused remedy. By contrast, among those whose "if only" conjecture focused on the machine en- vironment, only $13 \%$ decided on a human-focused remedy. The association between human-focused "if only" thoughts and human-focused remedies was highly significant $\left[\chi^{2}(1,58)=17.79, p<.001\right]$.

Experiment $1 \mathrm{~B}$ closely replicated the basic results of Experiment $1 \mathrm{~A}$ with a different sample of participants and a different response format. Again, we found that a substantial fraction of participants favored the humanfocused "if only" conjecture (48\%) and a substantial fraction favored the human-focused remedy $(34 \%)$. More importantly, the tendency toward human-focused remedies was far higher among participants whose "if only" thought focused on the human operator $(49 \%$ ) than among participants whose "if only" thought focused on the machine environment $(21 \%)$. The association between "if only" thought and remedy decision content reached a high level of statistical significance $\left[\chi^{2}(1,93)=8.10, p<.005\right]$.

\section{EXPERIMENT 2}

The results of Experiment 1 established an association between counterfactual thinking and later remedy decisions. Yet these results do not prove that remedy decisions are generated from "if only" conjectures. Three alternative interpretations for the effect in Experiment 1 could be raised. First, it could be argued that decisions about remedies come first in people's minds and "if only" thoughts are derived afterward to support preexisting remedy plans. Second, it could be argued that the association merely reflects an implicit pressure to be consistent across tasks. Third, asking for a counterfactual statement and asking for a remedy may be parallel ways of eliciting a single representation of the situation. Experiment 2 tests these interpretations by investigating whether priming counterfactual thoughts influences remedy decisions, whether influence runs in the opposite direction ("remedy primacy interpretation"), whether influence runs in both directions ("consistency pressure interpretation"), or whether both are influenced by a single representation of the situation ("common representation interpretation"). We predicted that there would be influence in the direction from counterfactual thoughts to remedy decisions, but not in the opposite direction. 
Table 2

Endorsement of Person- and System-Focused Remedies as a Function of Manipulated "If Only" Conjecture in Experiment 2A

\begin{tabular}{|c|c|c|c|c|c|c|}
\hline \multirow{3}{*}{$\begin{array}{l}\text { Remedy } \\
\text { Focus }\end{array}$} & \multicolumn{6}{|c|}{ Manipulated Subject of "If Only" Conjecture } \\
\hline & \multicolumn{2}{|c|}{ Person } & \multicolumn{2}{|c|}{ None } & \multicolumn{2}{|c|}{ Environment } \\
\hline & $M$ & $S D$ & $M$ & $S D$ & $M$ & $S D$ \\
\hline Retrain workers & $5.06_{a}$ & 1.60 & $4.73 \mathrm{a}$ & 1.64 & $4.37_{\mathrm{a}}$ & 2.03 \\
\hline Redesign line & $5.35_{\mathrm{a}}$ & 1.32 & $5.77_{\mathrm{ab}}$ & 1.27 & $6.21_{\mathrm{b}}$ & .98 \\
\hline Difference & $-.29 \mathrm{a}$ & 2.02 & $-1.04_{\mathrm{ab}}$ & 1.84 & $-1.84_{b}$ & 2.39 \\
\hline
\end{tabular}

Note-Different subscripts by row indicate significant differences in means $(p<.05)$.

\begin{abstract}
Method
Participants. In an experiment (Experiment $2 \mathrm{~A}$ ) testing whether remedy decisions are affected by priming of "if only" content, 62 undergraduate students were randomly assigned to conditions in which they were led to generate a human-focused counterfactual statement, no counterfactual statement, or an environment-focused counterfactual statement before making remedy decisions. In the comparison experiment (Experiment 2B), testing whether "if only" thoughts are affected by priming of remedy decision content, 73 undergraduates students were randomly assigned to conditions in which they generated a human-focused remedy, no remedy, or an environment-focused remedy before making a counterfactual conjecture.

Design, Procedure, and Materials. Participants began by reading the accident vignette. In the primary experiment $(2 \mathrm{~A})$, participants in one condition went directly to the remedy decision task, without being prompted to think counterfactually beforehand (no "if only" prompt). Participants in the other two conditions were prompted to complete a counterfactual conjecture with a particular conte:It focus: Participants generated a conjecture focusing either on the worker ("If only the worker__") or on the machine environment ("If only the assembly line__"). All participants rated two remedy decisions on 7-point scales, one tapping willingness to attempt a human-focused remedy and the other tapping willingness to attempt an environment-focused remedy.

The procedure of the second experiment (2B) simply inverted the independent and dependent variables. In two conditions, participants were first primed with human-focused or environmentfocused remedies by requiring them to complete a sentence describing a possible remedy (the sentences began, "I would try to train the workers to ___ or "I would try to redesign the assembly line to __). In the third condition, participants were not exposed to any possible remedies. In all three conditions, participants then rated the similarity of their own thoughts to two counterfactual conjectures (the counterfactuals were, "If only Paul had not reached up the line, this accident would not have happened," and, "If only the assembly line delivered the engines in a steady flow, this accident would not have happened").
\end{abstract}

\section{Results}

Table 2 shows the results from Experiment $2 \mathrm{~A}$ testing whether the counterfactual thoughts about an accident influence decisions about how to remedy the problem. As expected, the tendency to differentially endorse the human-focused remedy was greatest among participants who had been primed with human-focused "if only" conjectures and least among participants who had been primed with environment-focused conjectures. The linear contrast was significant $[F(1,59)=4.19, p<.05]$, reflecting that the two content-primed groups differed from each other $[t=-2.24, p<.05]$. Another way to summarize these data that facilitates comparison with previous studies is the percentage of participants who favored the humanfocused plan over the environment-focused plan, which was $24 \%$ in the human-focused counterfactual condition, $12 \%$ in the no-counterfactual condition, and $9 \%$ in the environment-focused counterfactual condition.

In contrast to Experiment $2 \mathrm{~A}$, there was no effect of the manipulation in Experiment $2 \mathrm{~B}$, which tested for influence of remedy decisions on endorsement of "if only" conjectures. The degree of focus on human action (measured by the difference between endorsement of human and environment counterfactuals) was nearly identical in the human-remedy prime condition $(M=-.30)$, the noprime condition $(M=-.31)$, and the environment-remedy prime condition $[M=-.54 \text {; contrast } F(1,70)=.18]^{5}$

\section{GENERAL DISCUSSION}

The present studies support the hypothesis that "if only" conjectures after accidents shape decisions about how to prevent recurrences. Experiment 1 documented the statistical association between the content of counterfactual conjectures and of remedy decisions. The causal link between the focus of an "if only" conjecture and that of remedy decisions was supported in Experiment $2 \mathrm{~A}$. In Experiment $2 \mathrm{~B}$, no support was found for three alternative explanations based on the ideas, respectively, that remedy decisions are cognitively prior to counterfactual conjectures, that participants always strive to maintain consistency of responses, and that asking for counterfactual statements and asking for remedy decisions are parallel means of eliciting a common representation of the situation.

We have argued that one reason to study the processes influencing accident remedy decisions is that psychological factors may contribute toward a tendency to focus narrowly on correcting "human error" after industrial accidents. In particular, we have suggested that "if only" conjectures are drawn toward human actions and hence may engender human-focused decisions at a greater rate than would occur otherwise. Our results are consistent with this argument. Experiment 1 documented that a substantial fraction of participants focused on human actions when generating an "if only" conjecture about an accident. This was the case even though the accident was designed to be one for which a narrowly human-focused plan would not be favored in a direct analysis of differing plans (and, in fact, was not favored by participants in the pilot study). Taken together with the evidence that conjectures influence subsequent decisions, the results lend credence to the argument that human-focused remedy decisions may occur as a by-product of human-focused "if only" conjectures. Given that these decisions have been identified as potentially problematic by accident researchers, it is important to consider their possible psychological roots.

\section{Implications for Theory}

The present research adds to the emerging literature on counterfactual thinking and decision making. Most 
past research on the relation between "if only" thinking and adaptive decision making has emphasized its salutary role. This has been the dominant message in theoretical statements (e.g., March, Sproull, \& Tamuz, 1991) and in empirical findings from performance domains (e.g., Morris \& Moore, 1998; Roese, 1994). These studies have emphasized that "if only" thoughts about a negative performance engender adaptive plans for avoiding recurrences of the outcome.

By contrast, the present research indicates that "if only" thoughts influence remedy plans, but it calls into question the adaptiveness of these plans. Our pilot study indicated that participants did not prefer human-focused remedy plans for the accident after a thorough analysis. Although there is no definitive basis for calling a plan better or worse in the case of a hypothetical accident, the pilot study suggests that participants recognize a humanfocused plan as worse. Yet, the "if only" conjectures generated by many participants in Experiment 1 led them to human-focused plans. Hence, our experiment illustrates a domain where "if only" thinking may impede participants from choosing the best decision option. Together with other recent empirical findings (Sim \& Morris, 1998) and theoretical analyses (Sherman \& McConnell, 1995), the present findings contribute to an emerging countervailing theme in the literature that decision making is not always well served by "if only" thinking. Instead, it is a mixed blessing for decision making - helpful in some domains, harmful in others.

\section{Issues for Future Research}

An important issue for future research is identifying the boundary conditions under which "if only" conjectures impede adaptive decision making about accidents. This research will clarify the benefits or costs of proceduresformal and informal - that encourage decision makers to generate "if only" conjectures about accidents. Given that "if only" conjectures may increase the likelihood of a focus on human actions, one candidate for a moderating variable is the efficacy of human-focused remedies in a given accident domain.

Another, more subtle, moderating variable may be the configuration of causes in a given accident domain. Here, the important aspect of "if only" conjectures is that compared with other ways of framing causal attributions for accidents, they lead to a narrower focus on one antecedent factor rather than a broader focus on multiple, interacting antecedent factors. Hence, "if only" conjectures may impede decision making when diagnostic narrowness is a liability. In other words, "if only" conjectures may engender inefficacious plans to prevent accident recurrences when the causal structure of the domain is complex (Jervis, 1996). The decisions that result would exemplify what Dörner (1997) has called "unconditionalized planning"-remedies that adjust one factor in a system without taking into account chain reactions that may cause new problems. In a recent investigation of such pitfalls, participants reacted to outcomes in a complex domain by following heuristic rules to generate counterfactual con- jectures. Consequentially, these conjectures focused on an antecedent factor that lacked any causal relation to the outcome and that participants themselves evaluated as erroneous upon later analysis (Morris, Sim, \& Moore, 1999). Adaptive learning from counterfactual thinking in complex domains may require that human intuition be bolstered by computer simulations of the causal configuration that enable exploration of interaction effects (Moore \& Thomsen, 1996).

Models of adaptive learning from counterfactual thoughts must consider the types of outcomes that provoke such thoughts. In addition to thoughts that "undo" accidents, there is potential relevance in thoughts that "undo" nonaccidents - that is, thoughts that posit an accident occurring after one has not. Under most circumstances, these conjectures are infrequent because the experience of a nonaccident lacks motivating or salient factors that would provoke counterfactual thinking. An exception, of course, is the class of nonaccidents that qualify as "near accidents." Indeed, research on aviation pilots' responses to near accidents observes the frequent occurrence of counterfactual thoughts about how it "could have been worse" as well as thoughts about how it "could have been better," yet only the latter, upward comparisons enabled adaptive learning (Morris \& Moore, 1998).

Although our focus heretofore has been the role of counterfactual thoughts in learning, learning is not the only function of counterfactual thinking, and it is an important project for future research to explore other functions. The kinds of counterfactuals that serve the function of learning differ from those which serve functions related to people's emotional needs. There is considerable evidence that the function of coping with negative affect is served by thoughts about how an outcome might have been worse (Roese \& Olsen, 1995). And, counterfactual conjectures can serve a person's motive of worldview preservation (Tetlock, 1998). For example, after an accident has occurred, one can preserve a belief that the setting is essentially safe by envisioning how the accident was almost averted.

In summary, future research on the psychology of counterfactual thinking and its interaction with the structure and content of domains may provide further insights into its role in adaptive learning and other functions. These insights, in turn, may elucidate the psychological processes underlying consequential patterns of decision making after accidents that have been described by organizational researchers.

\section{REFERENCES}

CARroll, J. (1995). Incident reviews in high-hazard industries: Sense making and learning. Industrial \& Environmental Crisis Quarterly, 9, 175-198.

DöRnER, D. (1997). The logic of failure: Recognizing and avoiding error in complex situations. Reading, MA: Addison-Wesley.

Gilbert, D. T., \& Malone, P. S. (1995). The correspondence bias. Psychological Bulletin, 117, 21-38.

Girotto, V., LegrenzI, P., \& Rizzo, A. (1991). Event controllability in counterfactual thinking. Acta Psychologica, 78, 111-133. 
Gladwell, M. (1996, January 22). Blowup. The New Yorker, pp. 32-36. JERVis, R. (1996). Counterfactuals, causation, and complexity. In P. E. Tetlock \& A. Belkin (Eds.), Counterfactual thought experiments in world politics (pp. 309-316). Princeton: Princeton University Press.

Kahneman, D., \& Miller, D. T. (1986). Norm theory: Comparing reality to its alternatives. Psychological Review, 93, 136-153.

KaHNEMAN, D., \& TVERSKY, A. (1982). The simulation heuristic. In D. Kahneman, P. Slovic, \& A. Tversky (Eds.), Judgment under uncertainty: Heuristics and biases (pp. 201-208). New York: Cambridge University Press.

KELLEY, H. H. (1967). Attribution theory in social psychology. In D. Levine (Ed.), Nebraska Symposium on Motivation (pp. 192-238). Lincoln: University of Nebraska Press.

MARCH, J. G. (1994). A primer on decision making: How decisions happen. New York: Macmillan.

MARCh, J. G., \& Simon, H. A. (1958). Organizations. New York: Wiley.

March, J. G., Sproull, L. S., \& Tamuz, M. (1991). Learning from samples of one or fewer. Organizational Science, 2, 1-13.

McGill, A. L. (1989), Context effects in judgments of causation. Journal of Persanality \& Social Psychology, 5, 189-200.

MoOre, P. C., \& Thomsen, J. (1996). Reliving the past through com putational simulation: Testing the accuracy of organizational counterfactual thinking. Unpublished manuscript.

MORRIS, M. W., \& MoORE, P. C. (1998). Learning from a brush with danger: Evidence that pilot learning from dangerous incidents is enabled by counterfactual thinking and hindered by organizational accountability (Research Paper No. 1492). Stanford University, Graduate School of Business.

Morris, M. W., Sim, D. L. H., \& Moore, P. C. (1999). Erroneous "if only " thoughts: Heuristics of counterfactual thinking lead to errors in diagnosing accidents. Unpublished manuscript.

National TRaffic SAFETy BoARd (1990). Annual review of aircraft accident data. U.S air carrier operations calendar year 1987 (Report No. NTSB/ARC-90/01, Government Accession No. PB 91/1 19693). Washington, DC: Author.

Norman, D. A. (1990, April 11). Cognitive science in the cockpit. Paper presented at the Aerospace Human Factors Symposium, NASA Ames Research Center, Moffet Field, CA.

NORMAN, D. A. (1992). Turn signals are the jacial expressions of automobiles. Reading, MA: Addison-Wesley.

Perrow, C. (1981). Normal accident at Three Mile Island. Society, $18(5), 17-26$.

PERROw, C. (1984). Normal accidents: Living with high risk systems. New York: Basic Books.

Reason, J. (1990). Human error. Cambridge: Cambridge University Press.

RoEse, N. J. (1994). The functional basis of counterfactual thinking. Journal of Personality \& Social Psychology, 66, 805-818.

ROESE, N. J. (1997). Counterfactual thinking. Psychological Bulletin, 121, 133-148.

ROESE, N. J., \& OlsON, J. M. (1995). Functions of counterfactual thinking. In N. J. Roese \& J. M. Olson (Eds.), What might have been: The social psychology of counterfactual thinking (pp. 169-197). Mahwah, NI: Erlbaum

Sherman, S. J, \& MCConnell, A. R. (1995). Dysfunctional implications of counterfactual thinking: When alternatives to reality fail us. In N. J. Roese \& J. M. Olson (Eds.), What might have been: The social psychology of counterfactual thinking (pp. 199-231). Mahwah, NJ: Erlbaum.

SiM, D L. H., \& Morris, M. W. (1998). Representativeness in counterfactual thinking: The principle that antecedent and outcome correspond in magnitude. Personality \& Social Psychology Bulletin, 24, 595-609.

SPECTER, M. (1997, August 20). Jeers sting Mir mission control which bemoans a money pinch. The New York Times, p. Al.

TETLOCK. P. E. (1998). Close-call counterfactuals and bejief-system de- fenses: I was not almost wrong but I was almost right. Journal of Personality \& Social Psychology, 75, 3, 639-652.

VaughaN, D. (1996). The Challenger launch decision: Risky technology, culture, and deviance at NASA. Chicago, IL: University of Chicago Press.

Wells, G. L., TAYlor, B. R., \& Turtle, J. W. (1987). The undoing of scenarios. Journal of Personality \& Social Psychology, 53, 421-430.

\section{NOTES}

1. Given these limitations, a natural question, of course, is why organizations promulgate the procedure of reconstructing accidents. Some scholars have argued that these procedures act as "rituals of reassurance" that bracket off the accident as a singular event and isolate responsibility to narrow factors within that event, thereby restoring confidence in the safety of normal operations (Gladwell, 1996; Perrow, 1984).

2. It is worth clarifying the selation between human-factor focus in "if only" thinking about accidents (Girotto, Legrenzi, \& Rizzo, 1991) and the correspondence bias in thinking about causes of action (Gilbert \& Malone, 1995). A similarity is that both biases involve an exaggeration of the extent to which outcomes arise from human actors as opposed to their environments. The two biases differ, however, in that human actions are the "effect" to be explained in the correspondence bias, whereas they are the "cause" ascribed to explain accidents in "if only" thinking.

3. Of course, in this example, the option of replacing the human actors may have been the only option that seemed economically feasible. In our experimental materials, we ensured that the economic considerations would not pull in favor of either human or nonhuman remedies. 4. Although the primary purpose of the pilot study was to assess participants' endorsement of human-focused and environment-focused remedies for the accident problem, we also explored several other factors to check their impact on participants' reactions to the vignette. To check an interpretation based on an implied demand, we varied whether the change to a new product was said to have "required" or merely to have "involved" changes to the work process. To check an interpretation based on implied comparison cases (McGill, 1989), we varied the presence of information about past accidents. Half of participants saw the story above, which makes no mention of previous accidents, whereas the other half saw a story with the added detail that similar accidents had occurred in the past, before the redesign. If the selection of a causal background is critical to participants' judgments about this case, then information about past accidents should change their question from "why the accident occurred now and not in the past" to "why the accident happened to Paul and not to other employees," shifting causal focus from the work environment to the worker's behavior. Analyses of the interactions of these variations with the within-subject variable revealed that participants' perception of the superior efficacy of changes to the environment was not moderated by these variations. That is, it made no difference whether adaptation to the new product was said to have "required" or merely to have "involved" the change to the manufacturing process $[F(1,50)=.63$, n.s. $]$. Likewise, it made no difference whether the story mentioned that accidents had also occurred in the past $[F(1,50)=.80$, n.s. $]$.

5. Although caution is always due in arguing from results supporting the null hypothesis, most of the reasons for this caution do not apply to the argument we derive from the contrasting results of Experiments $2 \mathrm{~A}$ and $2 \mathrm{~B}$. Because these studies differed only in that we inverted the manipulated and dependent variables, the null result cannot simply reflect a lack of clarity in the experimental materials. Nor is a lack of statistical power a compelling account because Experiment $2 \mathrm{~B}$ has a larger $N$ than Experiment $2 \mathrm{~A}$, yet has a much smaller effect size.

(Manuscript received June 25, 1998; revision accepted for publication August 4, 1999.) 